\title{
Heliphenes and Related Structures
}

\author{
Alexandru T. Balaban*,a and K. Peter C. Vollhardt*, \\ ${ }^{a}$ Texas A\&M University at Galveston, Department of Marine Sciences, 200 Seawolf Parkway, Galveston, TX 77553, \\ USA \\ ${ }^{b}$ Department of Chemistry, University of California at Berkeley, Berkeley, California 94720-1460, USA
}

\begin{abstract}
This review discusses from a qualitative viewpoint three-dimensional structures (hydrocarbons and carbon allotropes) that can be obtained from the 4,6,12-archimedean tiling of the Euclidean plane (graphenylene net) or that are related to subgraphs derived from the graphenylene net, insisting on helical structures called $[n]$ heliphenes with alternating 4- and 6-membered conjugated rings. Analogies with benzenoid [ $n$ ]helicenes allow proposals for non-planar heliphenerelated structures that have yet to be explored.
\end{abstract}

Keywords: Carbon allotropes, graphene, graphenylene, helicenes, heliphenes, phenylenes.

\section{INTRODUCTION: CARBON NETS, HELICENES, CIRCULENES, AND HELIPHENES}

A plane can be covered in three ways by one type of regular polygons, forming regular nets (Platonic tilings of the Euclidean plane) namely by triangles (tiling denoted by $3^{6}$, with vertices having degree 6 because six lines meet at every vertex), squares (tiling $4^{4}$, with vertices of degree 4 ), or hexagons (tiling $6^{3}$, a trivalent regular graph, having vertices of degree 3). The last net, with vertices occupied by $\mathrm{sp}^{2}-$ hybridized carbon atoms, corresponds to graphene [1, 2]. Portions of graphene (the honeycomb lattice) are carbon skeletons of polycyclic aromatic compounds (benzenoids). They have been classified into catafusenes, perifusenes, or coronafusenes according to their dualists being acyclic, 3membered-cyclic, or higher-membered-cyclic, respectively. Larger portions of graphene may be folded into threedimensional geometries such as nanocones, nanotubes, or toroidal structures. Special classes of catafusenes can be forced out of planarity, as will be discussed in the next paragraph about helicenes. An early article on possible carbon structures different from graphite or diamond was published by one of the present authors in 1968 [3], and it was followed by a few other reviews on the same topic [4-6].

$[n]$ Helicenes are benzenoid hydrocarbons with fascinating properties [7-10], including enormous values for their specific rotation. For $[n]$ helicenes, a plot of specific rotation versus $n$ has two humps and has a "maximum chirality" at $n$ $=14$ [11]. $[n]$ Helicenes may be defined as cata-condensed benzenoids with $n>5$ whose dualist graph notation is a series of digits $1[12,13]$. The resolution of [7]-, [8]-, and [9 ]helicenes was originally performed by Martin and coworkers using Pasteur's laborious method of picking out single

*Address correspondence to this author at the Texas A\&M University at Galveston, Department of Marine Sciences, 200 Seawolf Parkway, Galveston, TX 77553, USA; Tel: +1-409-741-4313; Fax +1(409)7414313; E-mail: balabana@tamug.edu

Department of Chemistry, University of California at Berkeley, Berkeley, California 94720-1460, USA; Tel: +1-510-642-0286: Fax: +1(510)6435208; E-mail: kpcv@berkeley.edu crystals, dissolving them, and looking at their optical rotation $[14,15]$. Since then many other and more efficient synthetic methods have been developed [7, 16], including photocyclizations of cis-stilbene derivatives with circularly polarized light providing optically active compounds $[17,18]$.

The syntheses of $[n]$ helicenes were reviewed by Martin [19], who prepared such compounds with up to $n=14$ benzenoid rings [20-22]. The racemization proves that their molecules are flexible; theoretical studies on the racemization barriers indicate that a methyl in position 1 of a pentaor hexahelicene raises the barrier to a value comparable with that of hexa- or heptahelicene, respectively [23].

Unlike the situation of many other benzenoids, the carbon scaffold of helicenes is not a portion of the graphene lattice. Thus, hexahelicene has two more carbon atoms than coronene (whose carbon framework is a portion of a graphene sheet). Whereas it is difficult to choose a first term for the $[n]$ helicenes (e.g. phenanthrene with $n=3$ ?), it is certain that hexahelicene with $n=6$ benzenoid rings, and all the next helicenes till the highest known member of this series, cannot have planar structures. Even pentahelicene does not have a planar structure because of steric hindrance due to its hydrogen atoms. Mezey and coworkers [24] calculated geometries of helicenes and related systems as models towards helical graphites with wider ribbons than a single benzenoid ring.

Helicenes have no "anthracenic subgraph" and therefore belong to the class of fibonacenes because their numbers of Kekulé structures are Fibonacci numbers [25]. Irrespective of the direction of kinks along the catafusenic dualist graph, as long as there is no zero in the dualist graph notation, all such catafusenes with the same number $n$ of benzenoid rings have the same numbers of Kekule structures, and they are therefore called isoarithmic [26] or isoresonant [27, 28].

Several theoretical studies on the aromaticity of helicenes reported that their non-planarity does not decrease markedly their stability [29, 30]. Schulman and Disch [31] compared the calculated energies of helicenes with their fibonacenic 
zigzag isomers called [ $n$ ]phenacenes up to $n=16$ and found that the energy of the latter are not much lower.

Heterohelicenes have been explored since Wynberg started his research on thia-analogues [32]. This research area has developed rapidly, and has been reviewed in book chapters by Rajca and coworkers [33] as well as by Sato and Arai [34]. Whereas azahelicenes and their azonia counterparts (review [35]) have racemization barriers comparable to those of the corresponding helicenes, introduction of 5membered rings as in the oxa-, thia-, and azathiahelicenes lowers these barriers; oxahelicenes have considerable lower barriers than thiahelicenes with the same number of rings [36]. New synthetic methods have been developed for obtaining regio-defined heterohelicenes [37-41].

Circulenes are peri-condensed aromatic hydrocarbons with a closed loop of angularly annelated benzenoid rings around an inner ring: [5] circulene is called corannulene, and [6] circulene is called coronene. With an inner 12-membered ring, one has a fragment of the graphenylene sheet which will be discussed in a later section as the antikekulene hydrocarbon [12] circulene or [6] phenylene.

Among the semiregular nets (Archimedean tilings of the Euclidean plane) that contain more than one regular polygon, three of them have degree 3 , and are denoted as (3, $\left.12^{2}\right),\left(4,8^{2}\right)$, and $(4,6,12)$. If the first tiling would be a carbon allotrope, it would be non-alternant and extremely strained, but the other two involving 4-, 6-, 8- and 12-membered rings would be alternant and less strained. The second tiling is shown in Fig. (1). The analogy with benzenoids can be extended to portions of this $\left(4,8^{2}\right)$-tiling, giving rise to $2 \mathrm{D}$ structures (cata-condensed, peri-condensed, or coronacondensed fragments), and to 3D-structures such as analogs of nanocones or, as shown in Fig. (2), nanotubes. The antiaromatic character of planar conjugated 4- and 8-membered rings, however, is expected to cause marked differences from benzenoids, destabilizing all planar structures.

At this point one should make a distinction between regular or semiregular tilings where all vertices are equivalent, which are discussed in the present paper, and non-regular tilings, where there are differences among vertices: one such

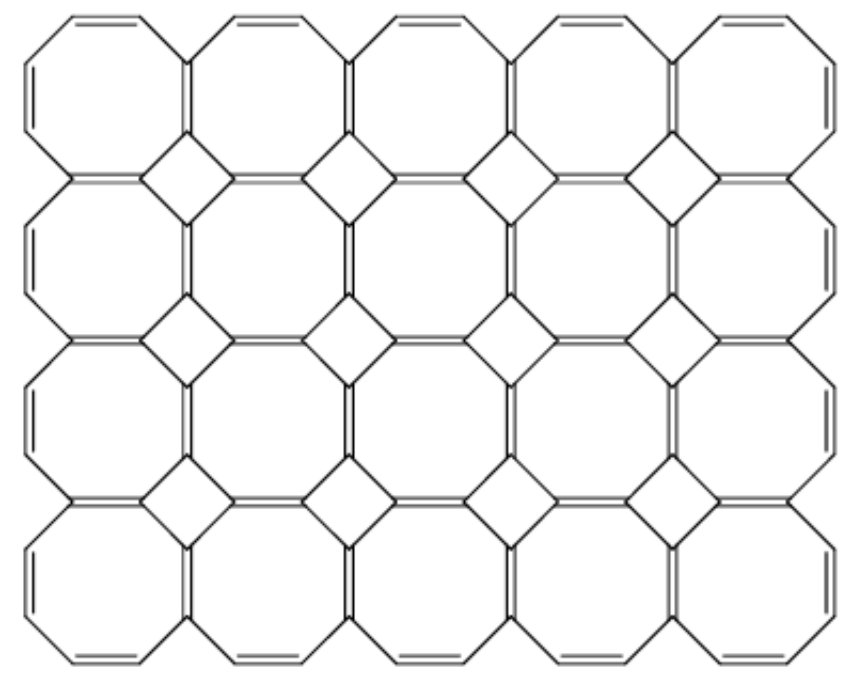

Fig. (1). The $4,8^{2}$-archimedean tiling of the Euclidean plane.
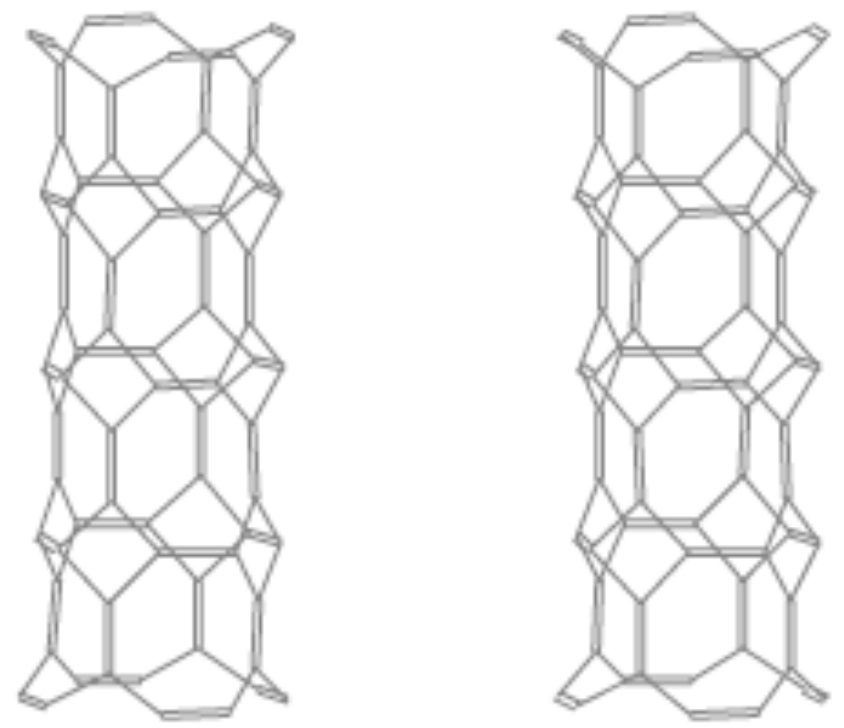

Fig. (2). Stereo-view of a nanotube formed from the $\left(4,8^{2}\right)$-net.

"biphenylene sheet" [42, 43] contains 4-, 6-, and 8-membered rings, and has a third of the vertices common to one 6membered and two 8-membered rings, with the remaining vertices common to one 4-membered, one 6-membered, and one 8-membered ring (therefore in order to make this net planar, these polygons cannot have normal bond angles). From this "biphenylene sheet" one cannot obtain bent or kinked $[n]$ phenylenes, because it contains only linear $[n]$ phenylene fragments. The "biphenylene dimer" (strictly speaking a bis-dehydro dimer), which is a fragment of this sheet, was synthesized by Rajca and coworkers, and its nonplanar structure was determined by X-ray crystallography of a tetra-tert-butyl derivative [44]. The parent is also formed by flash-vacuum isomerization of the angular [4] phenylene, as an intermediate in its flash-vacuum conversion into coronene [45].

$[\boldsymbol{n}]$ Phenylenes are portions of the semiregular $(4,6,12)$ tiling of the Euclidean plane: one may construct a theoretical analogue of a graphene sheet from biphenylene motifs in this tiling which is called graphenylene (Fig. 3) that has 12-, 6-, and 4-membered rings which provide a tiling of the Euclidean plane (three regular polygons with bond angles $150^{\circ}$, $120^{\circ}$, and $90^{\circ}$ meeting at a vertex) By analogy with graphitic nanotubes one can devise similarly constructed phenylenenanotubes. Two examples (presented in Figs. 4 and 5) result by rolling a rectangular portion of graphenylene around an axis that is oriented vertically or horizontally in Fig. (3) and connecting corresponding dangling bonds. By analogy with graphitic nanocones, one can consider phenylene-nanocones; an example of the "bluntest" such nanocone is shown in Fig. (6), resulting by cutting off a $60^{\circ}$ sector from the graphenylene sheet, and connecting dangling bonds in the remaining $300^{\circ}$ sector.

By counterbalancing the antiaromaticity of cyclobutadiene with the aromaticity of benzene (and possibly of the planar cyclodecapentaene), one can devise aggregates of 4- and 6-membered conjugated rings, which again can be grouped into cata-condensed, peri-condensed, or corona-condensed structures. A well-known planar molecule is biphenylene 
(dibenzocyclobutadiene), a stable compound (unlike cyclobutadiene and bicyclo[4.2.0]octatetraene, also called benzocyclobutadiene).

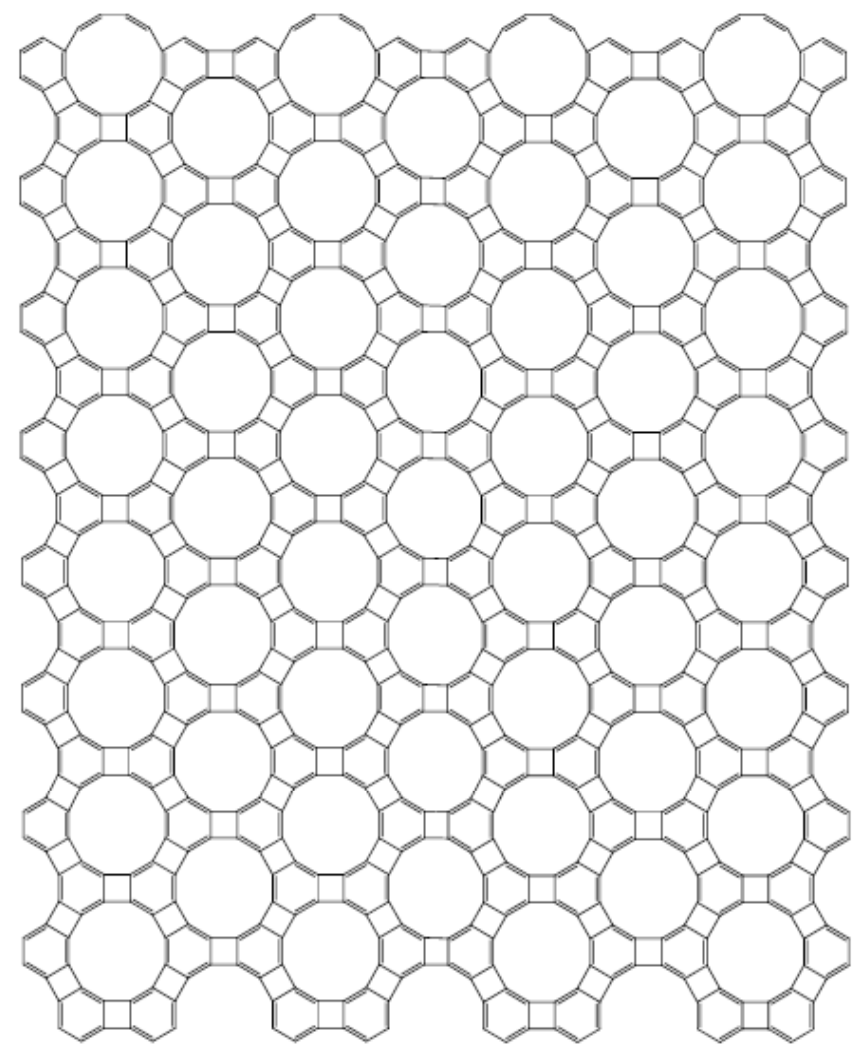

Fig. (3). A portion of the graphenylene sheet.
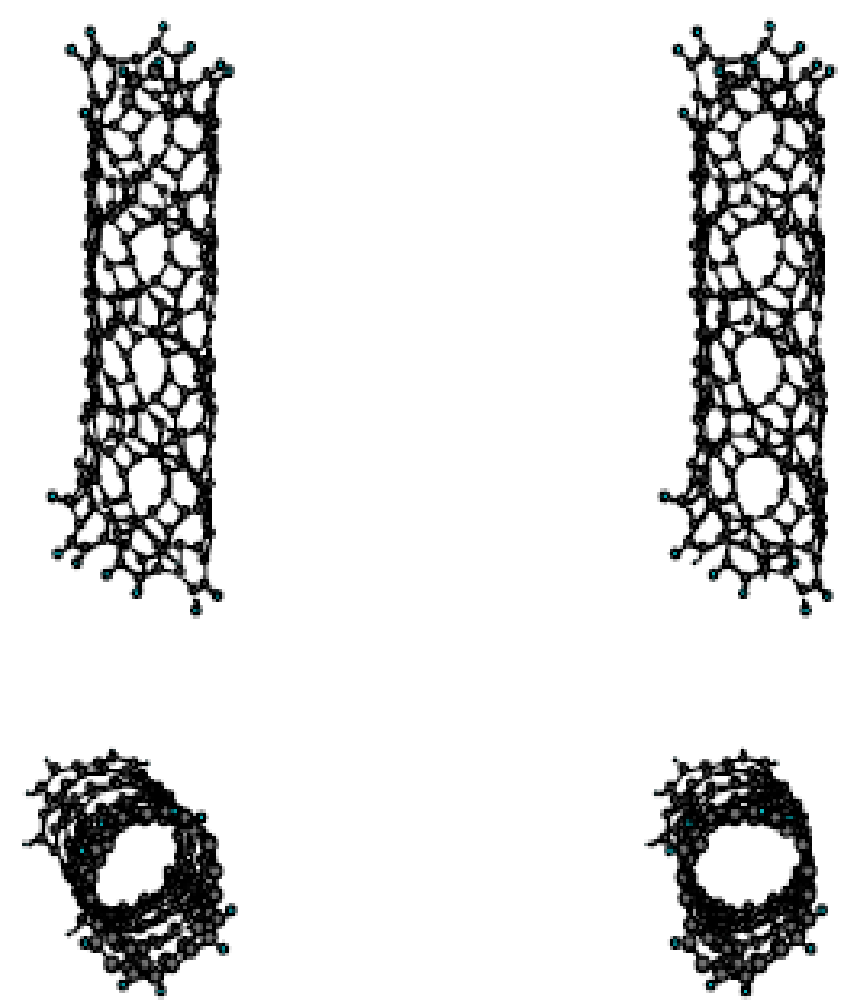

Fig. (4). Stereo-views of a zigzag phenylene-nanotube (analog of a single-wall zigzag graphitic nanotube).
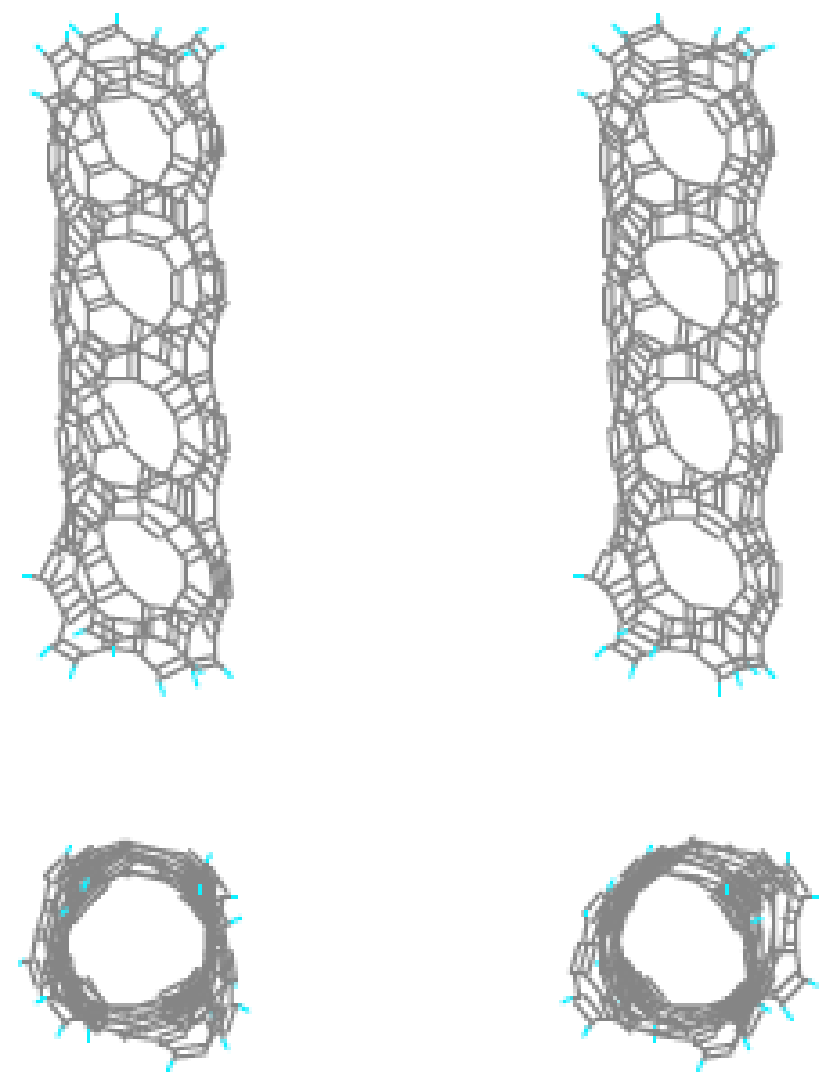

Fig. (5). Stereo-views of an armchair phenylene-nanotube (analog of a single-wall armchair graphitic nanotube).
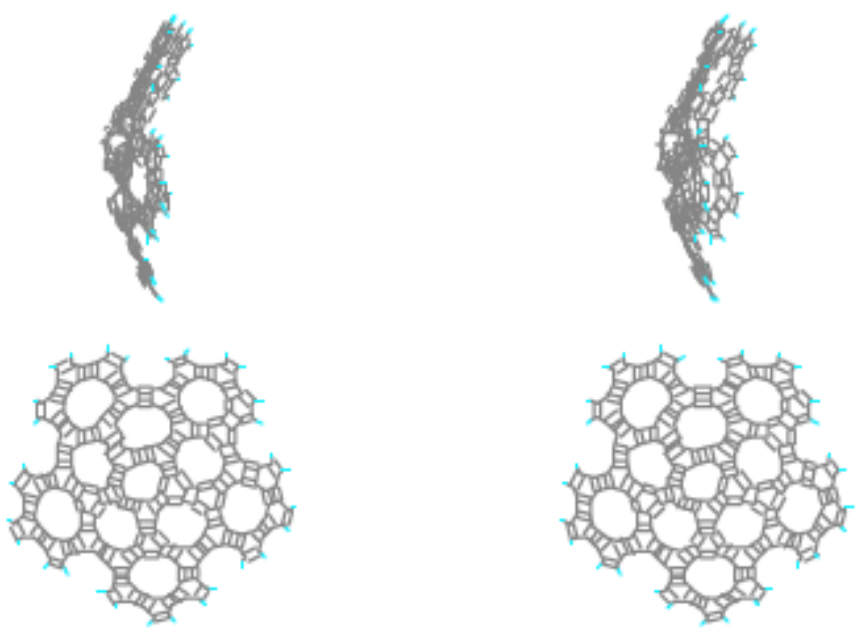

Fig. (6). Stereo-views of a phenylene-nanocone from 5 sectors of graphenylene.

Vollhardt and his coworkers have developed the rich and interesting chemistry of higher stable biphenylene homologues (" $[n]$ phenylenes"), in which condensed 4-membered rings alternate with benzenoid rings: reviews [46-48] and synthetic strategies [49-64]. Flash vacuum pyrolysis was an early method, which reached its limit at [4]phenylenes. The inter- and intramolecular cyclotrimerization of alkynes, catalyzed by various complexes of cyclopentadienylcobalt(dicarbonyl) or cyclopentadienylcobaltbis(ethylene), was much more successful. In the linear phenylene series, the 


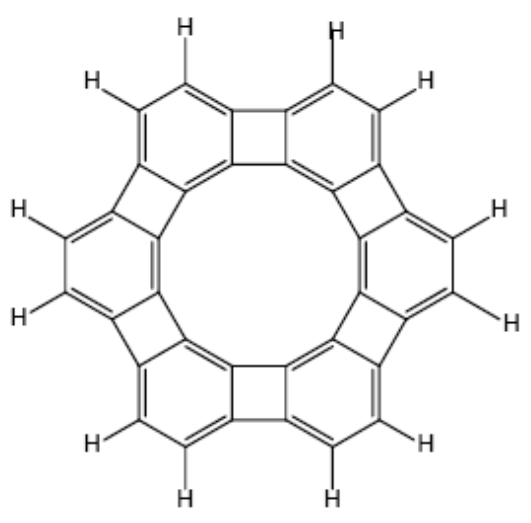

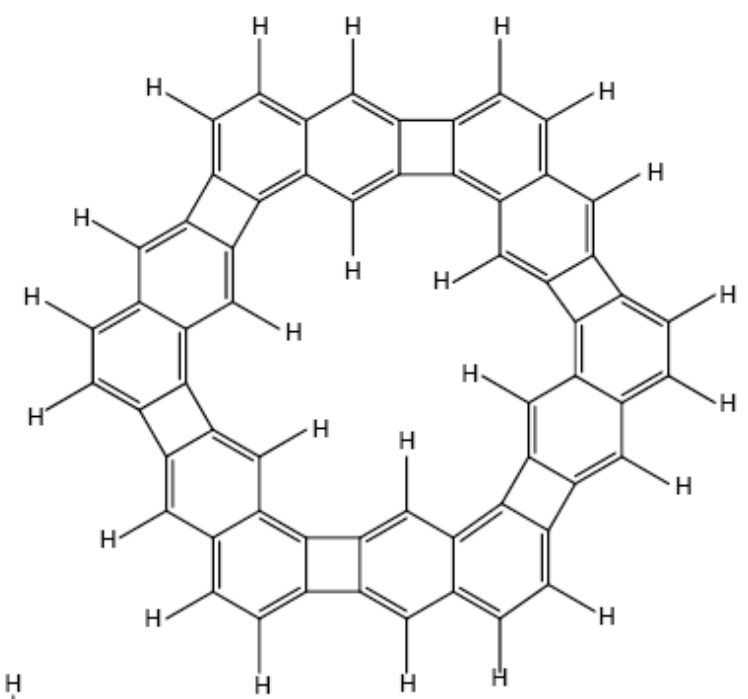

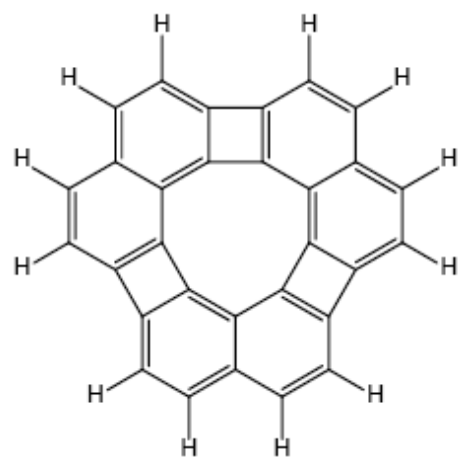

Fig. (7). Top row: cyclic [6]phenylene ("antikekulene") and cyclic [6]naphthylene with 4-membered rings having only exocyclic double bonds; bottom row: cyclic [3]naphthylene. Cyclic [6]naphthylene has also inner hydrogens.

electronically activated nature of the $\pi$-frame caused the metal to stay attached during the cyclization, requiring a separate demetallation step. Interesting haptotropic shifts of such cobalt- $\eta^{5}$-cyclopentadienyl complexes were observed [65].

For cata-condensed phenylenes, one may use a similar coding to that proposed for catafusenes based on digits 0 (for linear condensation) and 1, 2 (for left/right condensation) $[12,13]$. Other authors have discussed theoretical aspects of $[n]$ phenylenes:

Schulman and Disch provided extensive computations on energetic aspects and NMR chemical shifts [66-70]. Trinajstić et al. [71] have drawn attention to the fact that the HOMO-LUMO gap of linear $[n]$ phenylenes decreases rapidly with increasing $n$, unlike the behavior of zigzag $[n]$ phenylenes. Gutman proved that the "hexagonal squeeze" of the phenylene (replacement of the 4-membered ring by a double bond) that reduces a phenylene to a benzenoid has the interesting consequence that the algebraic structure count of a phenylene is equal to the Kekule structure count of the hexagonal squeeze [72]. Even more interesting is the fact that if the hexagonal squeeze is a "claromatic" benzenoid [73] (what Clar had called a fully-benzenoid hydrocarbon, with hexagons being either "empty" or having an aromatic sextet [74]), then the rings in the phenylene corresponding to the "empty" rings in the "claromatic" benzenoid have the weakest cyclic conjugation [75-79]. Thus such phenylenes behave as "anti-Clar structures".
Phenylene analogues of coronene ([6]circulene) and corannulene ([5]circulene) are displayed in Figs. (7 and 8), respectively. The former analog, which has not yet been obtained despite several attempts [80] (to be called $c y$ clo[6]phenylene) may be considered to represent "antikekulene", because the six 4-membered rings replace benzenoid rings in kekulene and because the major resonance contributor (avoiding double bonds in these rings, thus minimizing cyclobutadienoid character; see Fig. 7) accentuates peripheral "superdelocalization", both loops being also antiaromatic. On alternating higher acenes with 4-membered rings, one may imagine cyclic naphthylenes (Fig. 7), cyclic anthrylenes, etc. Phenylene analogues of the recently discovered allotropic forms of carbon, fullerenes such as buckminsterfullerene, can also be imagined [81, 82]. Fig. (9) presents a stereo-view of archimedene [83], in which a 10-, a 6-, and a 4-membered ring (regular polygons with bond angles $144^{\circ}$, $120^{\circ}$, and $90^{\circ}$ ) meet at a vertex. None of these phenylenic structures have yet been prepared.

\section{[n]Heliphenes}

Angular phenylenes can be considered to be related to fibonacenes. In particular, one can have angular $[n]$ phenylenes (henceforth called $[n]$ heliphenes) when the number of benzenoid rings is $n$, and the number of 4 membered rings is $n-1$. Thus, Fig. (10) presents [6]heliphene (hydrogen atoms in the latter cause the molecule to adopt a non-planar geometry) and Fig. (11) displays stereo-views of [12] heliphene. Starting with Fig. (10), a few 
of the following stereo-views no longer include explicitly hydrogen atoms in order to avoid cluttering of the drawings.
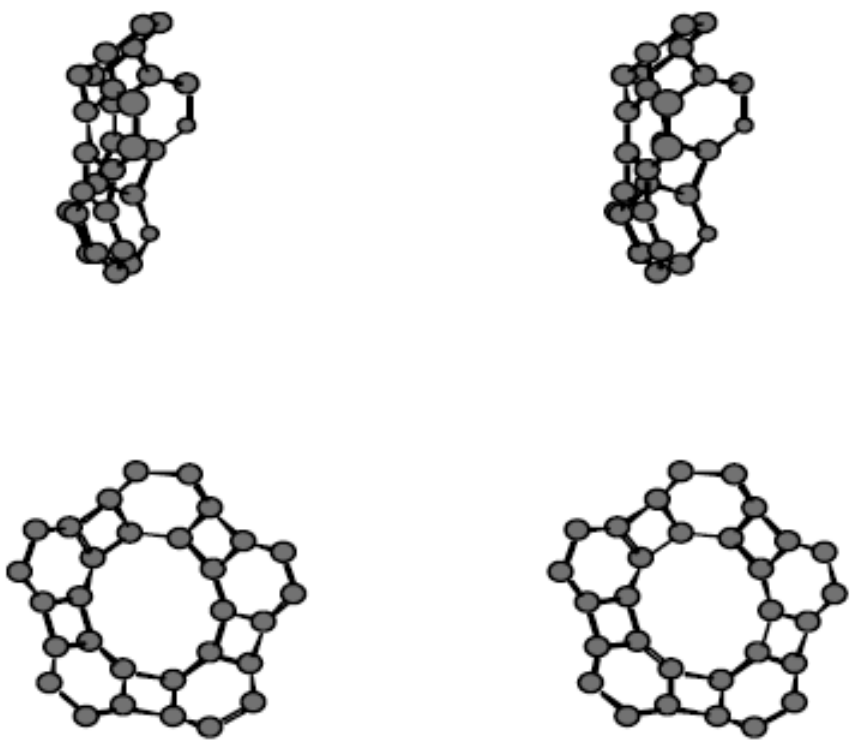

Fig. (8). Stereo-view (side and front views) of phenylene[5]circulene (analog of corannulene); the 10 hydrogen atoms are not shown.
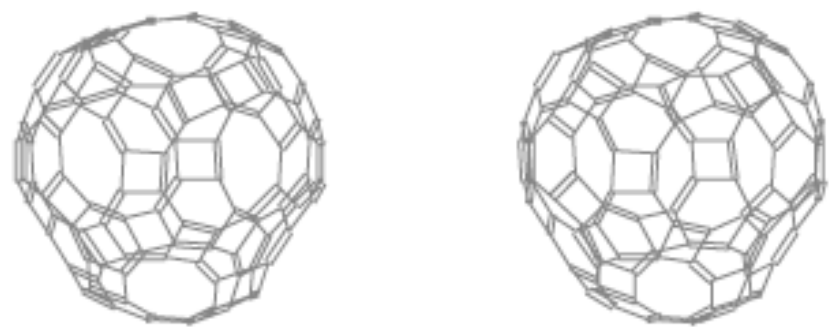

Fig. (9). Stereo-view of archimedene.

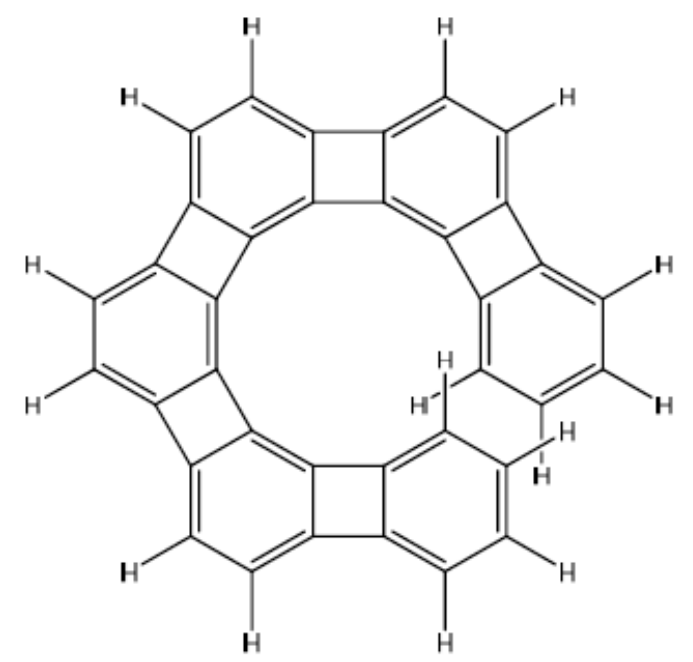

Fig. (10). [6]Heliphene.

Syntheses of [6]-, [7]-, [8]-, and [9] heliphenes have been reported by Vollhardt and coworkers [55,58], and theoretical considerations by Mezey and coworkers [24]. The present paper discusses structures that could be derived from heliphenes and may constitute the object of future synthetic
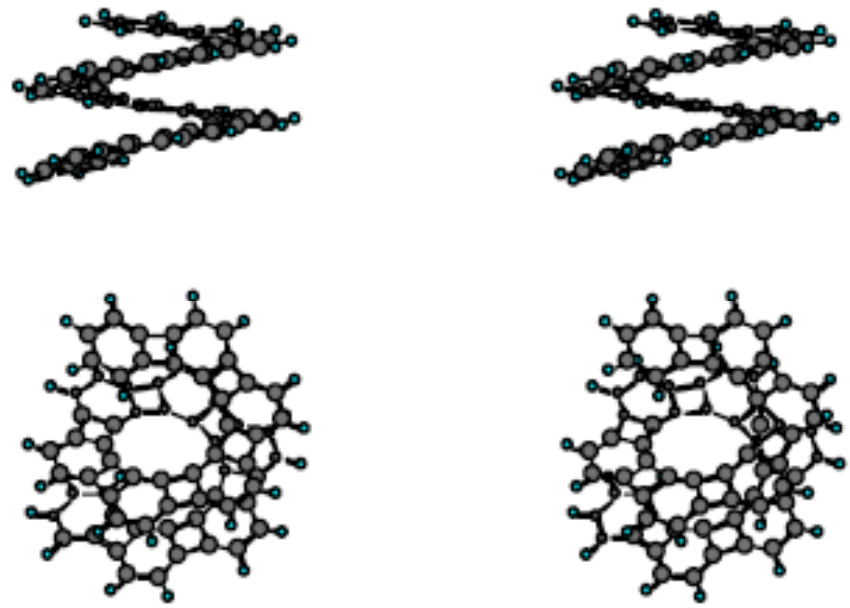

Fig. (11). Stereo-views of [12] heliphene (side and front view).

efforts. Another new challenging structure has benzenoid rings in phenylenes replaced by a higher catafusene (naphthalene, phenanthrene, anthracene, etc.). Fig. (12) presents the challenging [6]naphthylene, yet unknown.
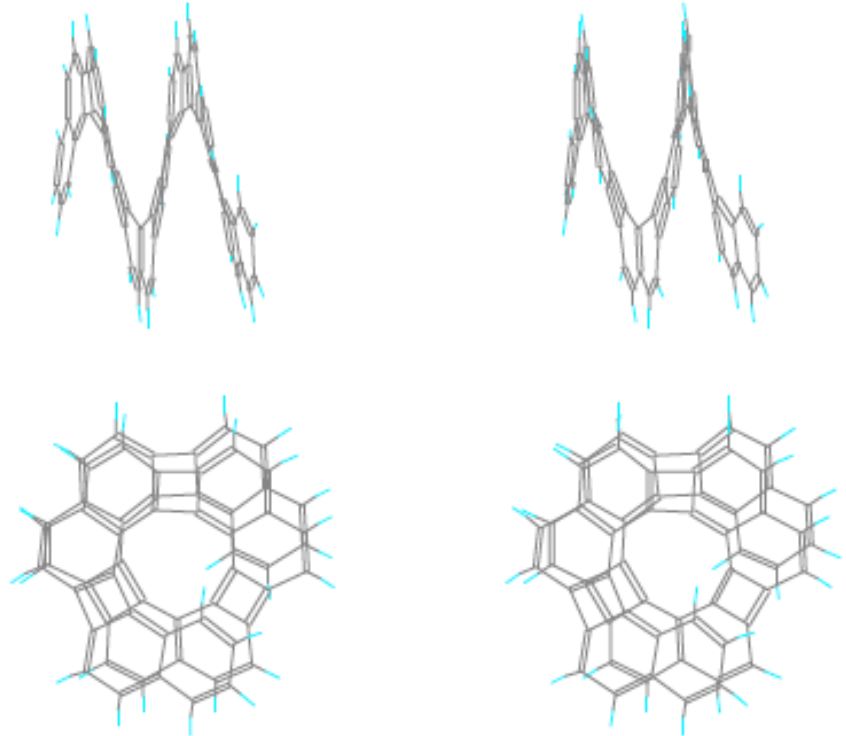

Fig. (12). Stereo-views of [6]helinaphthylene (side and front view).

\section{Double Helix Heliphenes}

Whereas DNA has two thread-like macromolecules held together by hydrogen bonds between purine and pyrimidine bases, one can imagine a double helix formed by two tapelike heliphenes held together by attractive $\pi$-electron interactions. Fig. (13) displays such a double helix from two [12]heliphenes.

\section{Intermolecular Dehydrogenation Products}

In a theoretical exploration of hypothetical intramolecular and intermolecular dehydrogenations of helicenes, interesting structures were published [84]. Wynberg and coworkers [85] had described dehydrohelicenes obtained from [5]and [6] helicenes by $\mathrm{AlCl}_{3}$-catalyzed intramolecular dehydrogenation (Scholl reaction [86]). In the benzenoid series, simi- 

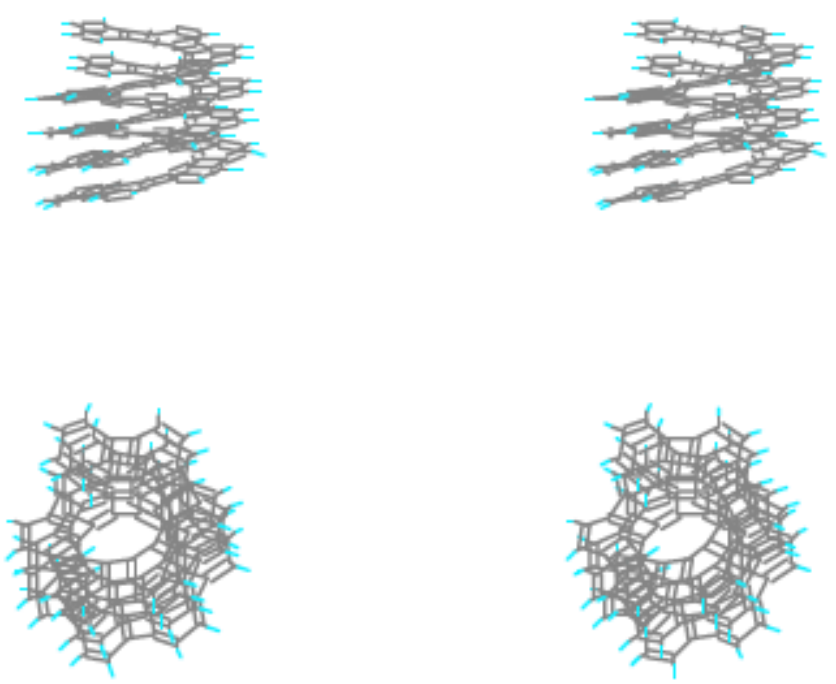

Fig. (13). Stereo-views of the double helix formed by two [12]heliphenes (side and front view).

lar reactions (with higher yields in the presence of $\mathrm{CuCl}_{2}$ which acts also as oxidant, in Kovacic-type reactions (dehydro coupling of aromatic rings [87]) have been carried out by Müllen and coworkers for obtaining experimentally large claromatic benzenoids [88].

By analogy, one can consider the product of intermolecular "straight-dehydrogenation" of the double helix that was presented in Fig. (10) (i. e. the new $\mathrm{C}-\mathrm{C}$ bonds are formed by eliminating hydrogens in a $2+2$ process resulting in new 4-membered rings); the product is a helical structure similar to a tobogan, displayed in Fig. (14). One may observe that there are four 4-membered rings condensed to an 8membered ring, in addition to benzenoid rings. When "intercalated-dehydrogenation" takes place (i. e. when the new C $\mathrm{C}$ bonds are formed by eliminating hydrogens in a $2+4$ process resulting in new 6-membered rings) the resulting structure should be more stable; Fig. (15) presents such a "loop-roller-coaster" structure. Colors in Fig. (15) help in observing that there are only 6-membered rings condensed with two 4-membered rings, and no 8-membered rings.
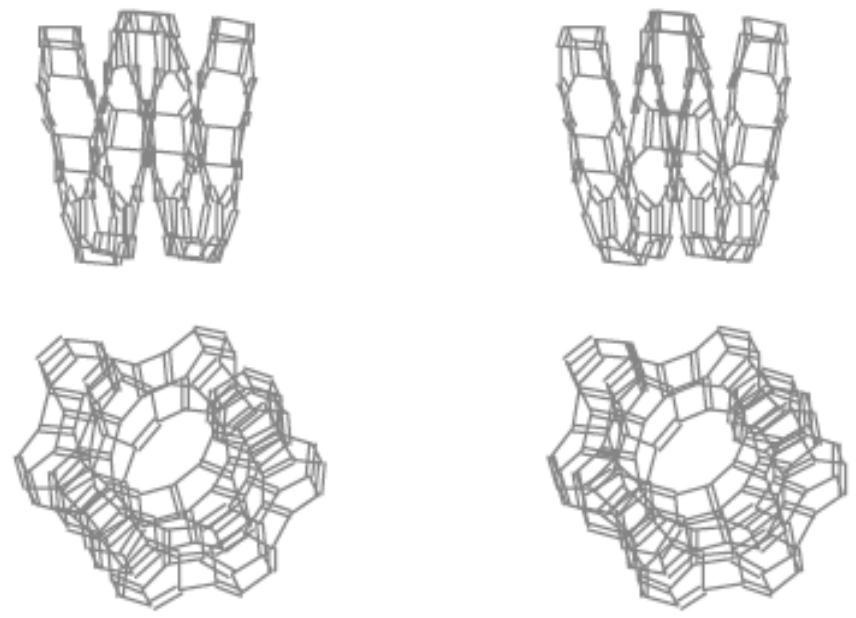

Fig. (14). Stereo-views (side and front views) of the result of intermolecular "straight-dehydrogenation" of the double helix from Fig. 10.
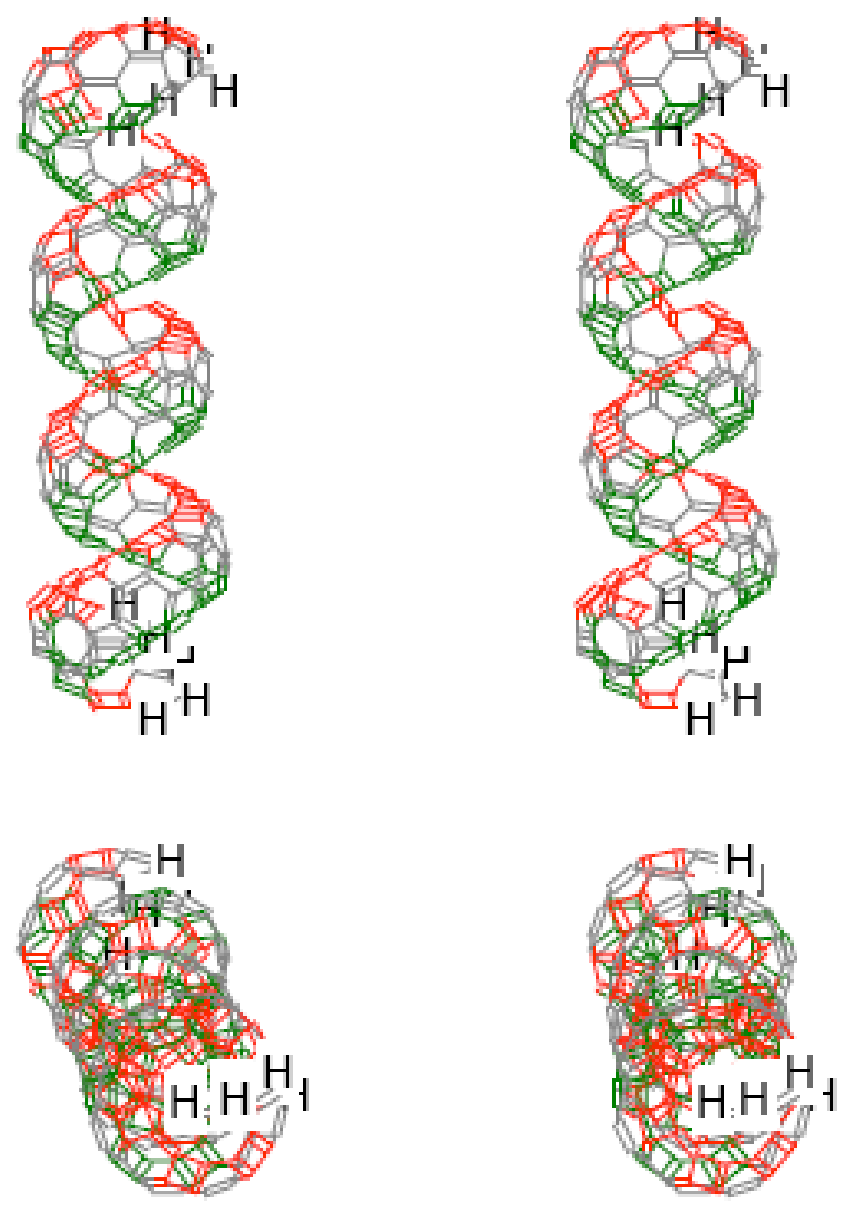

Fig. (15). Stereo-views of the result of intermolecular "intercalateddehydrogenation" of a double-helix heliphene.

Two parallel superimposed cyclo[n]phenylenes could form a cage carbon molecule in various ways. For cyclo[6]phenylenes, Fig. (16) presents a "straight" such dehydrogenation product with 4-, 6-,and 8-membered rings, and Fig. (17) displays an "intercalated-dehydrogenation" product having only 4- and 6-membered rings.
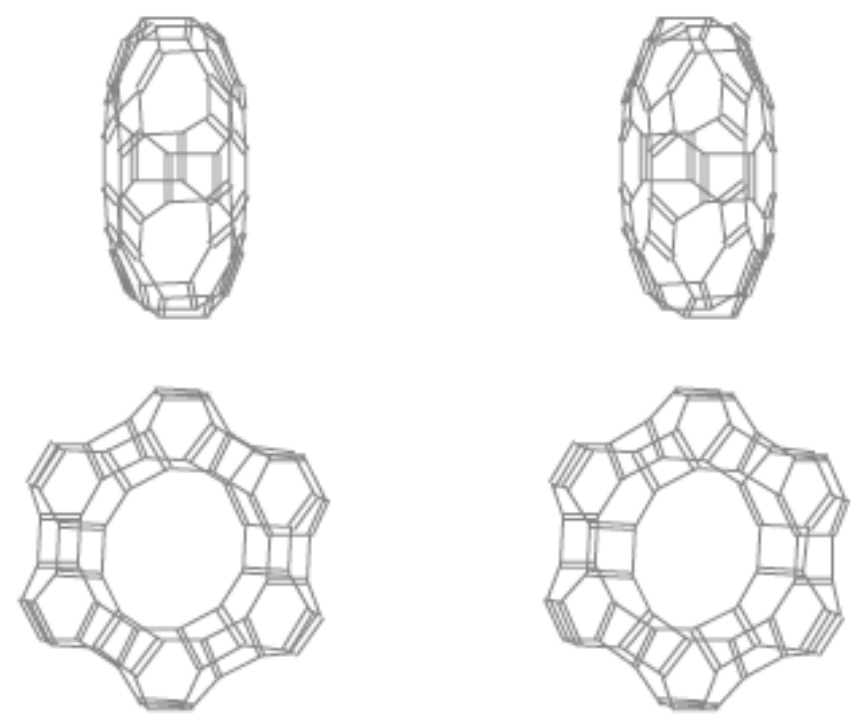

Fig. (16). Stereo-views (side and front view) of intermolecular "straight-dehydrogenation" of two cyclo[6]phenylenes. 

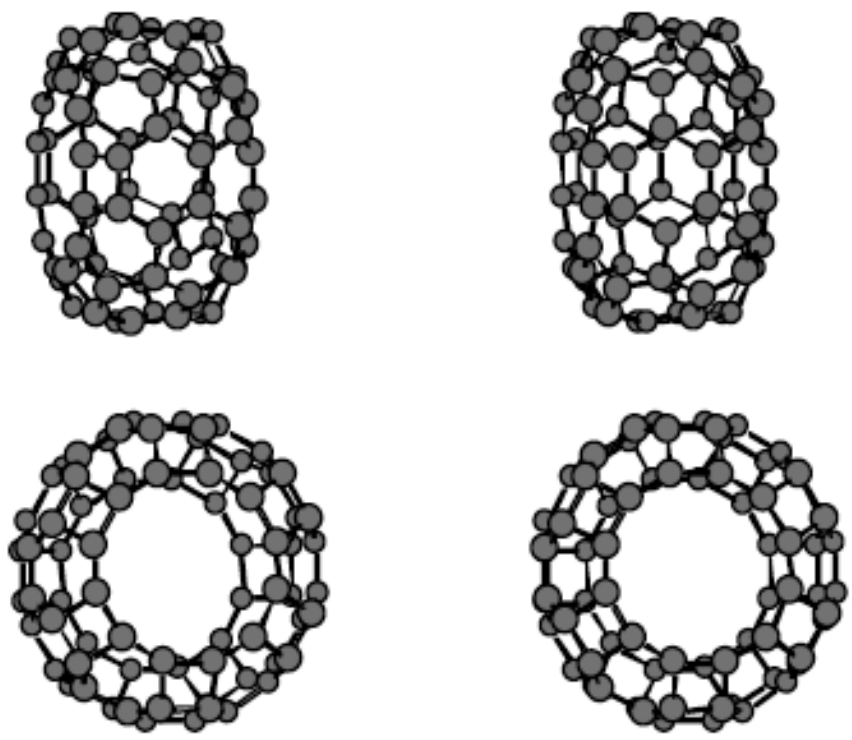

Fig. (17). Stereo-views (side and front view) of intermolecular "intercalated-dehydrogenation" of two cyclo[6]phenylenes.

\section{Intramolecular Dehydrogenation Products of Heliphenes}

If the hydrogen atoms on the periphery of heliphenes are "straight-eliminated" with the formation of new C-C bonds, one would obtain small "tobogan-like" structures with 4-, 6, and 8-membered rings (as shown in Fig. (18) from [12] heliphene). If intramolecular "intercalated dehydrogenation" takes place, the result is a similar structure which, however, has only 4- and 6-membered rings (Fig. 19).
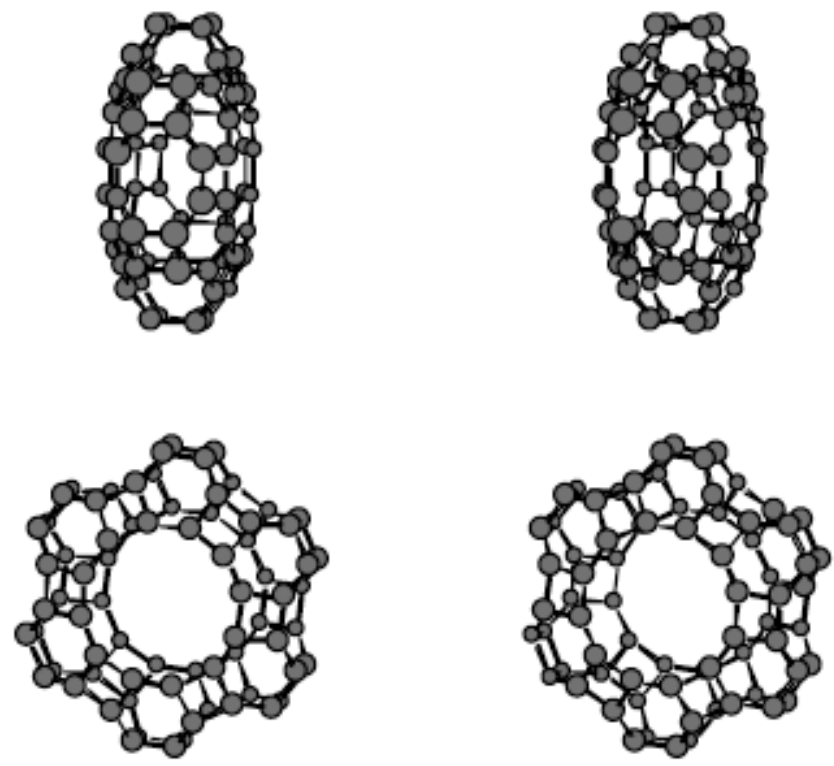

Fig. (18). Stereo-views (side and front view) of intramolecular "straight-dehydrogenation" of [12]heliphene.

One may consider "chain-polymers" of intermolecular dehydrogenation products of heliphenes, such as the dimer presented in Fig. (20).

Among all Platonic solids (regular polyhedra), only one regular polyhedron, namely the cube, can fill the threedimensional Euclidean space. The hexagonal prism formed
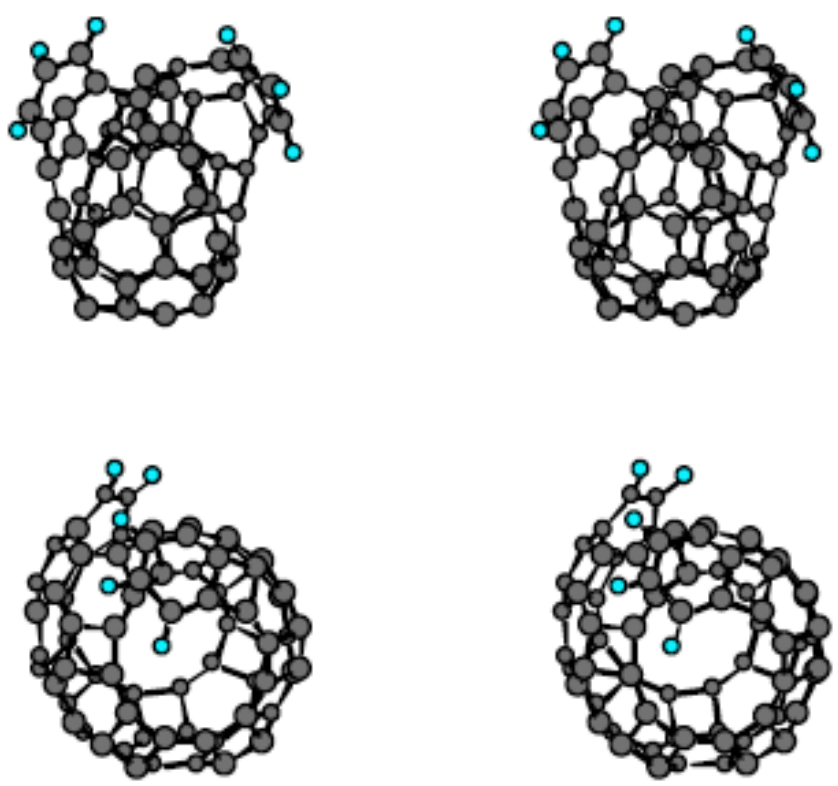

Fig. (19). Stereo-views (side and front view) of intramolecular "intercalated-dehydrogenation" of [12]heliphene.
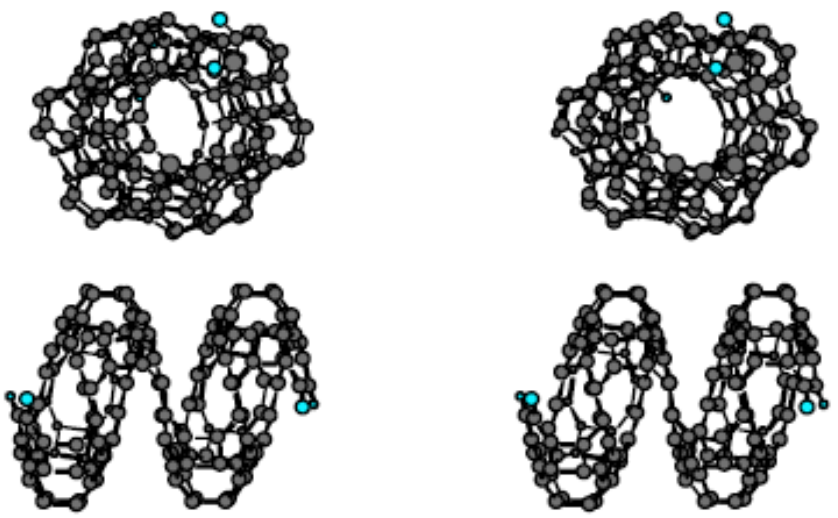

Fig. (20). Stereo-views of the dimer of the intramolecular straightdehydrogenation product of [12]heliphene.

from planar squares and hexagons also has this property. Among all Archimedean solids (semiregular polyhedra), only one can fill the three-dimensional Euclidean space, namely the truncated octahedron. Interestingly, this semiregular polyhedron could (in principle) be obtained from the zigzag [4]phenylene or from starphenylene via an intramolecular dehydrogenation as shown in Fig. (21), by elimination of all its 12 hydrogen atoms. The topologically easier conversion of the $\mathrm{C}_{3}$ symmetric [4]phenylene (also known as "starphenylene" [49]) into $\mathrm{C}_{24}$ was tried from the reduced species described in ref. [89]. Then the truncated octahedron $\left(\mathrm{C}_{24}\right.$ carbon cage presented in Fig. 22) can fill the $3 \mathrm{D}$ space by multiplication and conversion of all its carbon atoms from 3-coordination into 4-coordination. Neither this carbon cage, nor its perhydrogenated counterpart, a valence isomer of $(\mathrm{CH})_{24}$, is known.

A problem that is mentioned in connection with 3Dphenylenes and particularly with heliphenes is the possibility of obtaining knots or Möbius strips owing to the fact that phenylenes are very floppy [52]. Unlike helicenes, which 

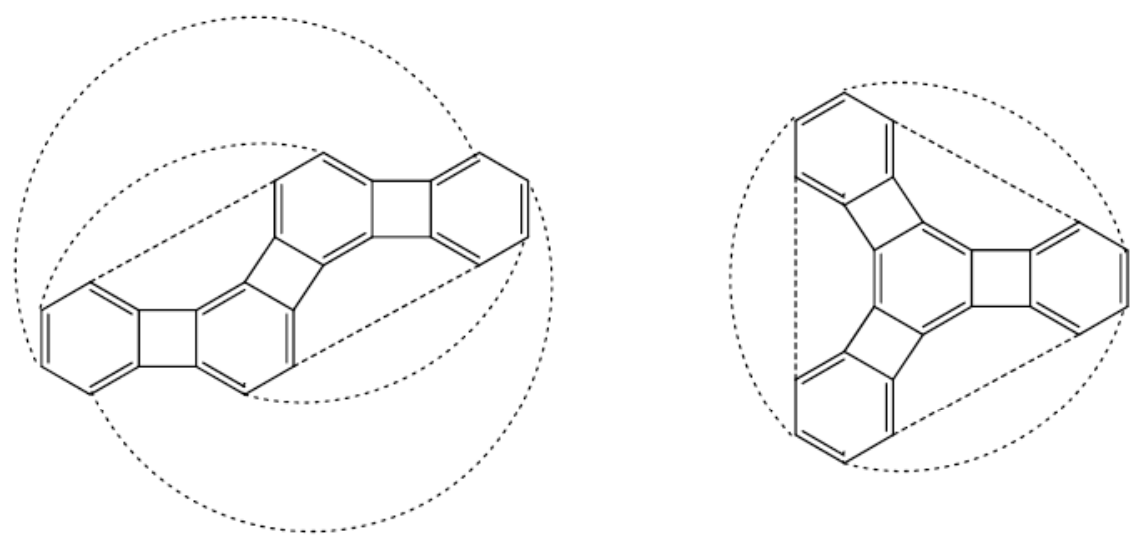

Fig. (21). How to convert portions of graphenylene by intramolecular dehydrogenation involving 12 hydrogen atoms, into the $\mathrm{C}_{24}$ cage shown in Fig. 22.

like all benzenoids, are fairly rigid so that helicenes afford stable enantiomers, heliphenes are very floppy and cannot be resolved into enantiomers $[55,58]$. In Fig. (23) one can see a stereo-view of a knot obtained theoretically by dehydrogenation of [12]helicenes: the bonds involved in the connection between 4- and 6-membered are severely deformed. Fig. (24) presents a stereo-view of a Möbius hydrocarbon isomeric with antikekulene and differing from it by reversing two C$\mathrm{C}$ bonds. It may be seen that with the exception of one twisted 4-membered ring the remainder of the molecule is almost planar.
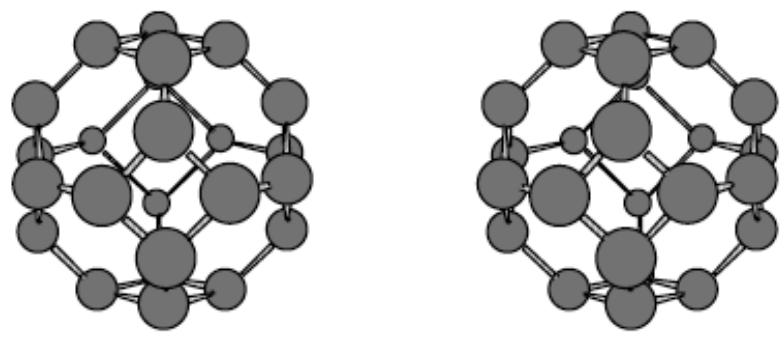

Fig. (22). Stereo-view of the $\mathrm{C}_{24}$ carbon cage (truncated octahedron), which can fill the $3 \mathrm{D}$ space by multiplication and conversion of all its carbon atoms from 3-coordination into 4-coordination.
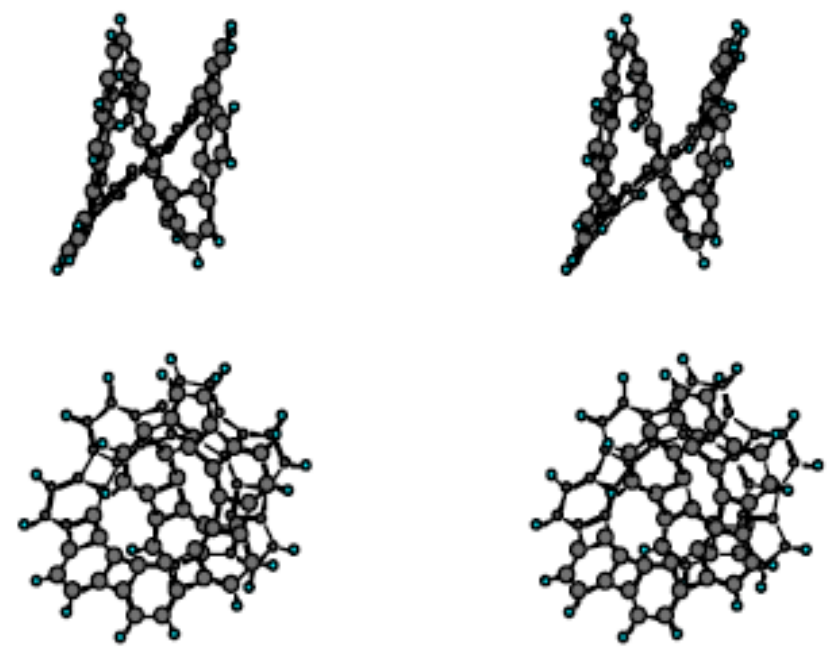

Fig. (23). Stereo-view (side and top views) of a phenylene knot formed from [12] heliphene by loss of four hydrogen atoms from the marginal 6-membered rings.
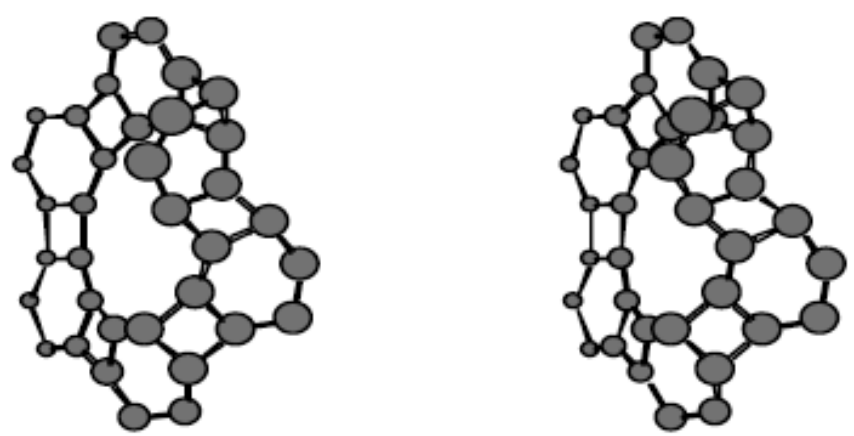

Fig. (24). Stereo-view of a Möbius hydrocarbon formed from antikekulene by reversing two $\mathrm{C}-\mathrm{C}$ bonds; the 12 hydrogen atoms are not shown.

Another difference between kekulene and antikekulene is the larger "hole" of the latter, which allows imagining a catenane-type interlocking of two such super-rings (Fig. 25).
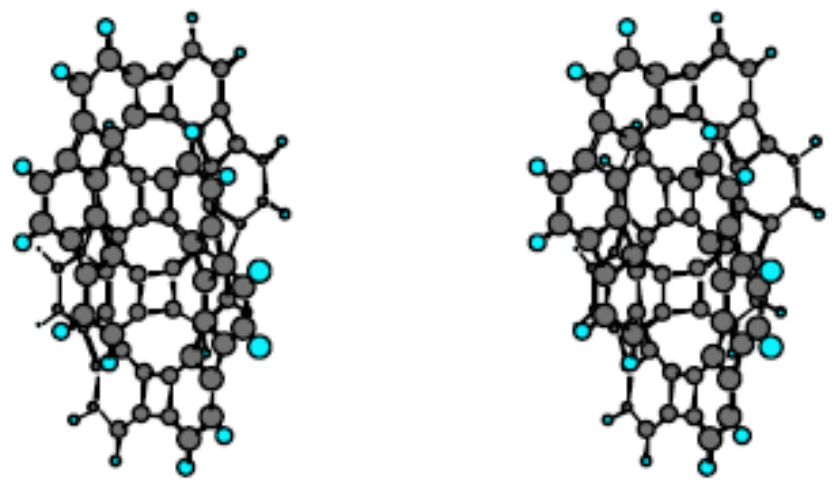

Fig. (25). Stereo-view of a catenane-type interlocking of two antikekulenes.

All stereo-views have been obtained by energy minimization using the Molecular Mechanics program MM2 (CambridgeSoft).

\section{CONCLUSIONS}

We have reviewed helicenes and heliphenes, and have discussed how phenylenes might be partly dehydrogenated into several challenging yet unknown structures. Despite 
their considerable steric strain, some of these structures might be synthetically accessible.

\section{CONFLICT OF INTEREST}

None.

\section{ACKNOWLEDGEMENT}

The financial assistance from NSF (CHE-0907800) is acknowledged by KPCV.

\section{REFERENCES}

[1] Geim, A. Graphene: status and prospects. Science, 2009, 324, 1530-1534.

[2] Allen, M. J.; Tung, V. C.; Kaner, R. B. Honeycomb carbon: a review of graphene. Chem. Rev., 2010, 110, 132-154.

[3] Balaban, A. T.; Rentea C. C.; E. Ciupitu, Chemical graphs. VI. Estimation of the relative stability of several planar and tridimensional lattices for elementary carbon. Rev. Roum. Chim., 1968, 13, 231-247 (Erratum, ibid., p. 1233).

[4] Balaban, A. T. Carbon and its nets. Computers Math. Applic., 1989, 17, 397-416. Reprinted in "Symmetry II" Hargittai, I. (Ed.), Pergamon Press, Oxford, 1989, pp. 397-416.

[5] Balaban, A. T. Theoretical investigation of carbon nets and molecules. In: Theoretical Organic Chemistry, Parkanyi, C. (Ed.), Elsevier, Amsterdam, 1998, pp. 381-404.

[6] Balaban, A. T. Theoretical investigations of single-wall nanocones. In: Nanostructures. Novel Architecture, Diudea, M. V. (Ed.), Nova Publishers, New York, 2005, pp.113-142.

[7] Newman, M. S.; Lednicer, D. The synthesis and resolution of hexahelicene. J. Am. Chem. Soc., 1956, 78, 4765-4770.

[8] Hopf, H. Classics in Hydrocarbon Chemistry: Syntheses, Concepts, Perspectives. Chapter 12, p. 321-336, Wiley-VCH, Weinheim, 2000.

[9] Katz, T. J.; Liu, L.; Willmore, N. D.; Fox, J. M.; Rheingold, A. L.; Shi, S.; Nuckolls, C.; Rickman, B. H. An efficient synthesis of functionalized helicenes. J. Am. Chem. Soc., 1997, 119, 1005410063.

[10] LeBas, G.; Navaza, A.; Knossow, M.; DeRango, C. 11-Helicene, $\mathrm{C}_{46} \mathrm{H}_{26}$. Cryst. Struct. Commun., 1976, 5, 713-718.

[11] Katznelson, O.; Edelstein, J.; Avnir, D.; Quantitative chirality of helicenes. Tetrahedron Asymmetry, 2000, 11, 2695-2704.

[12] Balaban, A. T.; Harary, F. Chemical graphs. V. Enumeration and proposed nomenclature of benzenoid cata-condensed polycyclic aromatic hydrocarbons. Tetrahedron, 1968, 24, 2505-2516.

[13] Balaban, A. T. Chemical graphs. VII. Proposed nomenclature of branched cata-condensed benzenoid polycyclic hydrocarbons. Tetrahedron, 1969, 25, 2949-2956.

[14] Martin, R. H.; Flammang-Barbieux, M.; Cosyn, J. P.; Gelbke, M. 1 - Synthesis of octa- and nonahelicenes. 2 - New syntheses of hexaand heptahelicenes. 3 - Optical rotation and O.R.D. of heptahelicene. Tetrahedron Lett., 1968, 9, 3507-3510.

[15] Martin, R. H.; Marchant, M. J. Resolution and optical properties $\left([\alpha]_{\max }, \mathrm{ORD}\right.$ and CD) of hepta-, octa- and nonahelicene. Tetrahedron, 1974, 30, 343-345.

[16] Sehnal, P.; Stará, I. G.; Šaman, D.; Tichý, M.; Mišek, J.; Cvačka, J.; Rulišek, L.; Chocholoušová, J.; Vacek, J.; Goryl, G.; Szymonski, M.; Císařová, I.; Starý, I. An organometallic route to long helicenes, Proc. Natl. Acad. Sci. USA, 2009, 106, 13169-13174. Corrections, ibid. 17605

[17] Kagan, H.; Moradpour, A.; Nicoud, J. F.; Balavoine, G.; Martin, R. H.; Cosyn, J. P. Photochemistry with circularly polarized light. (II) Asymmetric synthesis of octa- and nonahelicene. Tetrahedron Lett., 1971, 12, 2479-2482.

[18] Moradpour, A.; Kagan, H.; Baes, M.; Morren, G.; Martin R. H. Photochemistry with circularly polarized light - III. Synthesis of helicenes using bis(arylvinyl) arenes as precursors. Tetrahedron, $\mathbf{1 9 7 5}, 31,2139-2143$

[19] Martin, R. H. The helicenes. Angew. Chem. Int. Ed. Engl., 1974, 13, 649-659.

[20] Martin, R. H.; Libert, V. Helicenes. The use of resolved hexahelicene-2-carboxylic acid as a common precursor for the photochemical synthesis of pure octa-, nona-, deca-, undeca-, and tridecahelicenes. Thermal racemization of deca- and undecahelicenes. $J$. Chem. Res. (S), 1980, 130-131.

[21] Flammang-Barbieux, M. Nasielski, J. Martin, R. H. Synthesis of heptahelicene. (1) Benzo[c]phenanthro[4,3-g]phenanthrene. Tetrahedron Lett., 1967, 8, 743-744.
Martin, R. H. Baes, M. Helicenes. Photosynthesis of [11], [12] and [14] helicene. Tetrahedron, 1975, 31, 2135-2137.

[23] Janke, R. H.; Haufe, G.; Würthwein, E.-U.; Borkent, J. H. Racemization barriers of helicenes. A computational study. J. Am. Chem. Soc., 1996, 118, 6031-6035.

Wang, L.; Warburton, P. L.; Szekeres, Z.; Surjan, P.; Mezey, P. G.; Stability and properties of polyhelicenes and annelated fused-ring carbon helices: models toward helical graphites. J. Chem. Inf. Model., 2005, 45, 850-855.

[25] Balaban, A. T. Chemical graphs. Part 50. Symmetry and enumeraton of fibonacenes (unbranched catacondensed benzenoids isoarithmic with helicenes and zigzag catafusenes). MATCH Commun. Math. Comput. Chem., 1989, 24, 29-38.

[26] Balaban, A. T.; Tomescu, I. Algebraic expressions for the number of Kekulé structures of isoarithmic cata-condensed polycyclic hydrocarbons. MATCH Commun. Math. Comput. Chem., 1983 $14,155-182$.

[27] Živković, T. P.; Klein, D. J.; Schmalz, T. G. Isoresonant benzenoids. Polycyclic Arom. Comp., 2000, 18, 13-24

[28] 28. Živković, T. P.; Klein, D. J.; Schmalz, T. G. Covalent isoresonance. Polycyclic Arom. Comp., 2000, 13, 457-471.

[29] Randić, M.. Gimarc, B. M.. Nikolić, S.. Trinajstić, N. The aromatic stability of helicenic systems. Gazz. Chim. Ital., 1989, 119, 1-11.

[30] Aihara, J. Non-superaromatic reference defined by graph theory for a super-ring. J. Chem. Soc. Faraday Trans. 1995, 91, 237-239.

[31] Schulman, J. M.; Disch, R. L. Aromatic character of the $[n]$ helicenes and $[n]$ phenacenes, J. Phys. Chem. A, 1999, 103, 6669-6672.

[32] Wynberg, H. Some observations on the chemical, photochemical, and spectral properties of thiophenes. Acc. Chem. Res., 1971, 4, 6573.

[33] Rajca, A.; Miyasaka, M. Synthesis and Characterization of Novel Chiral Conjugated Materials. In: Functional Organic Materials: Syntheses and Strategies; Müller, T. J. J.; Bunz, U. H. F., Eds.; Wiley-VCH, Weinheim, 2007

[34] Sato, K.; Arai, S. Cyclophane Chemistry for the $21^{\text {st }}$ Century, Research Signpost, Kerala, India, 2002, pp. 173-197.

[35] Dumitrascu, F.; Dumitrescu, D. G.; Aron, I. Azahelicenes and other similar tri- and tetracyclic helical molecules. Arkivoc, 2010 (i) 132.

[36] Pieters, G.; Gaucher, A.; Maqrque, S.; Maurel, F.; Lesot, P.; Prim, D. Regio-defined amino[5]oxa- and thiahelicenes: a dramatic impact of the nature of the heteroatom on the helical shape and racemization barriers. J. Org. Chem., 2010, 75, 2096-2098.

[37] Katz, T. J. Syntheses of functionalized and aggregating helical conjugated molecules. Angew. Chem. Int. Ed., 2000, 39, 19211923.

[38] Urbano, A. Recent developments in the synthesis of helicene-like molecules. Angew. Chem. Int. Ed., 2003, 42, 3986-3989.

[39] Rajca, A.; Pink, M.; Xiao, S.; Miyasaka, M.; Rajca, S.; Das, K Plessel, K. Functionalized thiophene-based [7]helicene: chirooptical properties versus electonic delocalization. J. Org. Chem., 2009 74, 7504-7513.

[40] Rajca, A.; Wang, H.; Pink, M.; Rajca, S. Annelated heptathiophene: a fragment of a carbon-sulfur helix. Angew. Chem. Int. Ed., 2000, 39, 4481-4483.

[41] Miyasaka, M.; Pink, M.; Rajca, S.; Rajca, A. Noncovalent interactions in the asymmetric synthesis of rigid, conjugated helical structures. Angew. Chem. Int. Ed., 2009, 48, 5954-5957.

[42] Yousefi-Azari, H.; Yazdani, J.; Bahrami, A.; Ashrafi, A. R. Computing PI and Szeged indices of multiple phenylenes and cyclic hexagonal-square chain consisting of mutually ispomorphic hexagonal chain. J. Serb. Chem. Soc., 2007, 72, 1063-1067.

[43] Hudspeth, M. A.; Whitman, B. W.; Barone, V.; Peralta, J. E. Electronic properties of the biphenylene sheet and its one-dimensional derivatives. Nano, 2010, 4, 4565-4570.

[44] Rajca, A.; Safronov, A.; Rajca, S.; Ross II, C. R.; Stezowski, J. J. Biphenylene dimer. Molecular fragment of a two-dimensional carbon net and double-stranded polymer. J. Am. Chem. Soc., 1996 , $118,7272-7279$

[45] Dosa, P. I.; Gu, Z.; Hager, D.; Karney, W. L.; Vollhardt K. P. C. Flash-vacuum pyrolytic reorganization of angular [4]phenylene. Chem. Commun., 2009, 1967-1969.

[46] Vollhardt, K. P. C. The phenylenes. Pure Appl. Chem., 1993, 65 , 153-156.

[47] Vollhardt, K. P. C.; Mohler, D. L. The phenylenes: synthesis, properties, and reactivity. In: Advances in Strain in Organic Chemistry, Halton, B. (Ed.), JAI Publ., London, 1996, vol. 5, pp. 121-160.

[48] Miljanić, O. Š.; Vollhardt, K. P. C. [ $N]$ Phenylenes: a novel class of cyclohexatrienoid hydrocarbons. In: Carbon-Rich Compounds, Ha- 
ley, M.; Tykwinski, R. (Eds.), Wiley-VCH, Weinheim, 2006, chapter 4, pp. 140-197.

[49] Diercks, R.; Vollhardt, K. P. C. Tris(benzocyclobutadieno)benzene, the triangular [4]phenylene with a completely bond-fixed cyclohexatriene ring: cobalt-catalyzed synthesis from hexaethynylbenzene and thermal ring opening to 1,2:5,6:9,10-tribenzo3,4,7,8,11,12-hexadehydro[12] annulene. J. Am. Chem. Soc., 1986, $108,3150-3152$.

[50] Matzger, A. J.; Vollhardt, K. P. C. From phenylenes to acenes: flash vacuum pyrolyic isomerization of angular [3]phenylene to benzo[ghi]fluoranthene. Chem. Commun., 1997, 1415-1416.

[51] Eickmeier, C.; Holmes, D.; Junga, H.; Matzger, A. J.; Scherhag, F.; Shim, M.; Vollhardt, K. P. C. A novel phenylene topology: total syntheses of zigzag [4]- and [5]-phenylene. Angew. Chem. Int. Ed., 1999, 38, 800-804.

[52] Holmes, D.; Kumaraswamy, S.; Matzger, A. J.; Vollhardt, K. P. C. On the nature of nonplanarity in the [N]phenylenes. Chem. Eur. J., 1999, 5, 3399-3412.

[53] Schleifenbaum, A.; Feeder, N.; Vollhardt, K. P. C. The X-ray crystal structure of linear [3] phenylene. Tetrahedron Lett., 2001, 42, 7329-7332.

[54] Dosa, P. I.; Schleifenbaum, A.; Vollhardt, K. P. C. Isomerization of linear to angular [3]phenylene and PAHs under flash vacuum pyrolysis conditions. Org. Lett., 2001, 3, 1017-1020.

[55] Han, S.; Anderson, D. R.; Bond, A. D.; Chu, H. V.; Disch, R. L.; Holmes, D.; Schulman, J. M.; Teat, S. J.; Vollhardt, K. P. C.; Whitener, G. D. Total syntheses of angular [7], [8]-, and [9]phenylene by triple cobalt-catalyzed cycloisomerization: Remarkably flexible heliphenes. Angew. Chem. Int. Ed., 2002, 41, 3227-3230.

[56] Bong, D. T.-Y.; Gentric, L.; Holmes, D.; Matzger, A. J.; Scherhag, F.; Vollhardt, K. P. C. Synthesis of bent [4]phenylene (cyclobuta[1, 2-a:3,4-b']biphenylene) and structure of a bis(trimethylsilyl) derivative: the last [4]biphenylene isomer. Chem. Commun., 2002, 278-279.

[57] Dosa, P. I.; Whitener, G. D.; Vollhardt, K. P. C. Cobalt-mediated synthesis of angular [4]phenylene structural characterization of a metallacyclopentadiene(alkyne) intermediate and its thermal and photochemical conversion. Org. Lett., 2002, 4, 2075-2078.

[58] Han, S.; Bond, A. D.; Disch, R. L.; Holmes, D.; Schulman, J. M.; Teat, S. J.; Vollhardt, K. P. C.; Whitener, G. D. Total syntheses and structures of angular [6]- and [7]phenylene: The first helical phenylenes (heliphenes). Angew. Chem. Int. Ed., 2002, 41, 3223-3227.

[59] Bruns, D.; Miura, H.; Vollhardt, K. P. C. En route to archimedene: total synthesis of $C_{3 h}$-symmetric [7]phenylene. Org. Lett., 2003, 5, 549-552.

[60] Bong, D. T.-Y.; Chan, E. W. L.; Diercks, R.; Dosa, P. I.; Haley, M. M.; Matzger, A. J.; Miljanić, O. Š.; Vollhardt, K. P. C.; Bond, A. D.; Teat, S. J.; Stanger, A. Syntheses of syn and anti doublebent [5]phenylene. Org. Lett., 2004, 6, 2249-2252.

[61] Kumaraswamy, S.; Jalisatgi, S. S.; Matzger, A. J.; Miljanic, O. S.; Vollhardt, K. P. C. Anatomy of a cyclohexatriene: chemical dissections of the $\pi$ and $\sigma$ frame of angular [3]phenylene. Angew. Chem. Int. Ed., 2004, 43, 3711-3715.

[62] Botek, E.; Champagne, B.; Turki, M.; André, J.-M. Theoretical study of the second-order nonlinear optical properties of [N]helicenes and [N]phenylenes. J. Chem. Phys., 2004, 120, 2042-2048.

[63] Kumaraswamy, S.; Stanger, A.; Vollhardt, K. P. C. 1,2,3,4Tetraethynylbenzene as a template for cobalt-catalyzed alkyne cocyclizations: synthesis of 2,3,8,9-tetrakis(trimethylsilyl) angular [3]phenylenes and bent [5]phenylenes (benzo[1",2";3,4;3", 4";3',4']dicyclobuta[1,2-b:1',2'-b']bisbiphenylene). Synlett, 2006, 2981-2984.

[64] Dosche, C.; Mickler, W.; Löhmannsröben, H.-G.; Agenet, N.; Vollhardt, K. P. C. Photoinduced electron transfer in [N]phenylenes. J. Photochem. Photobiol. A. Chem., 2007, 188, 371-377.

[65] Albright, T. A.; Dosa, P. I.; Grossmann, T. N.; Khrustalev, V. N.; Oloba, O. A.; Padilla, R.; Paubelle, R.; Stanger, A.; Timofeeva, T. V.; Vollhardt, K. P. C., Photo-thermal haptotropism in cyclopentadienylcobalt complexes of linear phenylenes: First examples of in- tercyclobutadiene metal migration, Angew. Chem. Int. Ed., 2009, 48, 9853-9857.

[66] Schulman, J. M.; Disch, R. L. Theoretical studies of the [N]phenylenes. J. Am. Chem. Soc., 1996, 118, 8470-8474.

[67] Schulman, J. M.; Disch, R. L. Energetics of the [N]phenylenes with application to helical conformers. J. Phys. Chem. A, 1997, 101, 5596-5599

[68] Schulman, J. M.; Disch, R. L.; Jiao, H.; Schleyer, P. v. R. Chemical shifts of the [N]phenylenes and related compounds. J. Phys. Chem. A, 1998, 102, 8051-8055.

[69] Schulman, J. M.; Disch, R. L. Limiting properties of the [N]phenylenes, J. Phys. Chem. A, 2003, 107, 5223-5227.

[70] Schulman, J. M.; Disch, R. L. A theoretical study of large planar $[N]$ phenylenes, J. Phys. Chem. A, 2007, 111, 10010-10014.

[71] Trinajstić, N.; Schmalz, T. G.; Živković, T. P.; Nikolić, S.; Hite, G. E.; Klein, D. J.; Seitz, W. E. [N]Phenylenes. A theoretical study. New J. Chem., 1991, 15, 27-31.

[72] Gutman, I. Easy method for the calculation of the algebraic structure count of phenylenes. J. Chem. Soc. Faraday Trans., 1993, 89, 2413-2416.

[73] Balaban, A. T.; Klein, D. J. Claromatic carbon nano-structures. $J$. Phys. Chem. C, 2009, 113, 19123-19133.

[74] Clar, E. The Aromatic Sextet. Wiley, London, 1972, Chapter 6, pp. 28-31.

[75] Gutman, I. Clar theory and phenylenes. J. Mol. Struct. (Theochem), 1997, 389, 227-232.

[76] Gutman, I. Cyclic conjugation energy effects in polycyclic $\pi$ electron systems. Monatsh. Chem., 2005, 136, 1055-1069

[77] Gutman, I. A regularity for the total $\pi$-electron energy of phenylenes. MATCH, Commun. Math. Comput. Chem., 1994, 31, 99110.

[78] Gutman, I.; Dömötör, G. Wiener number of polyphenyls and polyphenylenes. Z. Naturforsch., 1994, 49A, 1040-1044.

[79] Gutman, I. The topological indexes of linear polyphenylenes. $J$. Serb. Chem. Soc., 1995, 60, 99-104.

[80] Diercks, R.; Vollhardt, K. P. C. Novel synthesis of the angular [3]phenylene by cobalt-calalyzed cyclization of bis(2ethynylphenyl)ethyne: a molecule with an internal cyclohexatriene ring. Angew. Chem. Int. Ed., 1986, 25, 266-268.81. Schulman, J. M.; Disch, R. L. Bowl-shaped hydrocarbons related to $\mathrm{C}_{60}, J$. Comp. Chem., 1998, 19, 189-194.

[81] Schulman, J. M.; Disch, R. L. Properties of phenylene-based hydrocarbon bowls and archimedene, J. Phys. Chem. A, 2005, 109, 6947-6952.

[82] Schulman, J. M.; Disch, R. L. Archimedene. Chem. Phys. Lett., 1996, 262, 813-816.

[83] Balaban, A. T. Theoretical examination of new forms of carbon formed by intra- or intermolecular dehydrogenation of polycyclic aromatic hydrocarbons. Polycyclic Arom. Comp., 2003, 23, 277296.

[84] Doper, J. H.; Oudman, D.; Wynberg, H. Dehydrogenation of heterohelicenes by a Scholl type reaction. The dehydrohelicenes. $J$. Org. Chem., 1975, 40, 3398-3401.

[85] Balaban, A. T.; Nenitzescu, C. D. Dehydrogenating Condensations of Aromatics (Scholl and Related Reactions), In: Friedel-Crafts and Related Reactions (Olah, G. A., Ed.), Wiley-Interscience, NewYork, 1964, vol. 2. pp. 979-1047.

[86] Kovacic, P.; Jones, M. B. Dehydro coupling of aromatic nuclei by catalyst-oxidant systems: poly(p-phenylene). Chem. Rev., 1987, 87, 357-379.

[87] Watson, M. D.; Fechtenkötter, A.; Müllen, K. Big is beautiful "aromaticity" revisited from the viewpoint of macromolecular and supramolecular benzene chemistry. Chem. Rev., 2001, 101, 12671300.

[88] Eichberg, M. J.; Houk, K. N.; Lehmann, J.; Leonard, P. W.; Märker, A.; Norton, J. E.; Sawicka, D.; Vollhardt, K. P. C.; Whitener, G. D.; Wolff, S., The thermal retro[2+2+2]cycloaddition of cyclohexane activated by triscyclobutenannelation: concerted alldisrotatory versus stepwise conrotatory pathways to fused [12]annulenes, Angew. Chem. Int. Ed., 2007, 46, 6894-6898. 